\title{
Influence of Solvent Exchange Drying Method on Mixed Matrix Membrane for Gas Separation
}

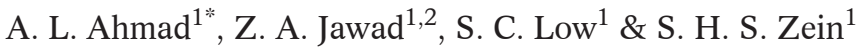 \\ ${ }^{1}$ School of Chemical Engineering, Engineering Campus, Universiti Sains Malaysia, Seri Ampangan, 14300 \\ Nibong Tebal, S.P.S. Penang, Malaysia \\ ${ }^{2}$ Nanotechnology and Advanced Materials Research Center, The University of Technology, 10066 Baghdad, Iraq
}

\begin{abstract}
The improvement of the $\mathrm{CO}_{2}$ separation efficiency from flue gases has been identified as a high-priority research area, to reduce the total energy cost of sequestration technologies in coal-fired power plant. Among the separation techniques, membrane technology, in particular mixed matrix membrane (MMM) appeared as the most attractive module due to its high separation capabilities (inorganic fillers) and economical processing materials (polymeric membrane). In this study, MMM was synthesized from cellulose acetate polymer with functionalized multi walled carbon nanotubes served as the inorganic fillers by wet phase inversion. Both vacuum drying and ethanol-hexane exchange drying methods were compared to investigate their influence on the MMM morphologies and properties. Experimental findings (FESEM, AFM and ATR-FTIR) showed that the ethanol-hexane exchange drying was an appropriate method to minimize morphology change of MMM, whereas the vacuum drying caused the greatest shrinkage to MMM structure. The $\mathrm{CO}_{2}$ permeance results supported the proposed solvent exchange mechanism where MMM with solvent exchange drying showed to have improved in their mechanical strength and better permeance of (733.90-741.67) GPU compared to the vacuum drying (18.72-18.44) GPU within pressure range of 1 to 3 bars.
\end{abstract}

Keywords: Gas separation, mixed matrix membrane, vacuum drying, solvent exchange drying, morphology

\subsection{INTRODUCTION}

Cellulose acetate (CA) is a thermoplastic polymer having both acetyl and hydroxyl groups that allows different types and degree of intra and intermolecular interactions with useful properties. CA membrane is famous with its characteristics of high selectivity, hydrophilic and high solubility in common organic solvents, where it has a widespread applications for reverse osmosis, ultrafiltration and gas separation [1].

CA membranes are suitable for gas separation. However, water contained within CA membrane

*Corresponding to: A. L. Ahmad (email: chlatif@eng.usm.my) is difficult to removed due to its asymmetric structure [2]. Therefore, a lot of efforts have focused on improving the drying methods of CA membrane for gas separation [3]. Riley et al. [4] reported the replacement of water in a wet CA membrane with carbon tetrachloride by liquid extraction to obtain dry CA membrane. However, this method is time consuming. Quick-freezing and vacuum sublimation at about $-10^{\circ} \mathrm{C}$ to dry CA membrane was considered by Gantzel and Merten [5], where the separation factor of $\mathrm{He} /$ $\mathrm{N}_{2}$ was successfully improved to 34 . In addition, Lui et al. [6] found the critical pore size on the surface of wet CA membrane was became smaller by applying different solvent exchange, in turns, 
resulting in higher $\mathrm{CO}_{2} / \mathrm{CH}_{4}$ separation factor. In the same solvent exchange method, Jie et al. [3] reported higher separation factor for $\mathrm{H}_{2}$ / $\mathrm{N}_{2}$ and $\mathrm{H}_{2} / \mathrm{CH}_{4}$ by using cellulose hollow fiber membrane.

In this regards, ethanol-hexane exchange drying method appeared to be one of the most feasible method due to its relative simplicity and satisfied results [3]. Under this method, ethanol was first replaced the water within CA membrane. Then, a second volatile solvent (hexane) was implied and replaced the first solvent. The second solvent is subsequently evaporated to obtain the dry membrane. The reason of replacing the water with ethanol followed by hexane is to minimize the capillary force inside the pore [2] and to reduce the surface tension during the drying process, thus, the structure of CA membrane will not collapse [7].

Nowadays scientists are moving their eyes to introduce mixed matrix membrane (MMM) in order to overcome the narrow scopes of polymeric and inorganic membranes [8]. Whereby, the separation properties of inorganic components such as zeolite, carbon molecular sieves, and carbon nanotubes (CNTs) [9-13] have the potential to achieve higher selectivity and/ or permeance relative to existing polymeric membranes [14].

The challenging of the current work is to develop dry MMM synthesized from CA polymer and functionalized multi walled CNTs (MWCNTs-F) for gas separation. Both vacuum drying and ethanol-hexane exchange drying methods were compared in terms of the membrane morphologies and $\mathrm{CO}_{2}$ permeation performance.

\subsection{METHODS}

\subsection{Materials}

Cellulose acetate (CA, acetyl content: (54.6-56)\% was acquired from Sinopharm Chemical Reagent Co. Ltd., China). Acetic acid $\left(\mathrm{CH}_{3} \mathrm{COOH}\right)$, ACS reagent $\geq 99.7 \%$, was supplied by Sigma Aldrich (Malaysia). MWCNTs-Pristine (MWCNTs-P) of $95 \%$ purity with average inner and outer diameters of approximately $8.85 \mathrm{~nm}$ and 26.62 $\mathrm{nm}$, respectively, were purchased from Shenzhen Nanotech Port Co. Ltd, China. Beta-cyclodextrin $(\beta-C D), n$-hexane and ethanol were supplied by Merck (Malaysia).

\subsection{Mixed matrix membrane preparation (MMM)}

MMM was fabricated by solution blending method [15]. $0.32 \mathrm{wt} \%$ functionalized MWCNTs [16] was added into $89.68 \mathrm{wt} \%$ of solvent mixture of $\left(\mathrm{CH}_{3} \mathrm{COOH}\right.$ :deionized water, $\left.70: 30\right)$ and sonicated for $20 \mathrm{~min}$ to obtain better particle distribution. The suspension was further stirred for $4 \mathrm{~h}[12,17] .10 \mathrm{wt} \%$ of CA was added gradually into the suspension and stirred at $55^{\circ} \mathrm{C}$ for $3 \mathrm{~h}$ until it was completely dissolved. The solution was then cooled to room temperature $\left(27^{\circ} \mathrm{C}\right)$ and further stirred for another $12 \mathrm{~h}$. Casting was carried out at room temperature with a constant thickness of $250 \mu \mathrm{m}$ using an automatic film applicator (Elcometer 4340, European Union), and immersed into coagulation bath (deionized water) for a period of $5 \mathrm{~min}$. Later, this sample was transferred to another water bath and immersed for $24 \mathrm{~h}$ to remove excess solvent present [18].

\subsection{Drying MMM}

Vacuum drying and ethanol-hexane exchange drying methods were carried out. The vacuum drying was carried based on Zhang et al. [18], whereby MMM was dried in vacuum oven for 1 $\mathrm{h}$ at $70^{\circ} \mathrm{C}$ and the resultant membrane (M1) was placed in air conditioned room for $3 \mathrm{~h}$ before storage. For the ethanol-hexane exchange drying method, the as spun MMM was immersed in fresh ethanol first for $4 \mathrm{~h}$ followed by immersing in fresh $\mathrm{n}$-hexane for $1 \mathrm{~h}$. The resultant membrane (M2) was then placed between two glass plates at room temperature $\left(27^{\circ} \mathrm{C}\right)$ for $24 \mathrm{~h}$ and stored prior to use.

\subsection{Characterization}

In order to analyze the membrane morphology, field emission scanning electron microscope (FESEM, SUPRA TM 35vp Zeiss, Germany) 
was used. For FESEM micrographs, membrane sample was first fractured using liquid nitrogen, then subjected to sputter coated with platinum. Membrane thickness and dense skin layer of the samples was measured using ImageJ software (1.32j, USA). An atomic force microscope (AFM, ParkScientific, Korea, XE-100) was utilized to analyze the surface microstructure roughness of the membranes. The membranes were cut into pieces of $2 \mathrm{~cm}$ by $2 \mathrm{~cm}$ and placed on specific sample holders. Areas of $5 \mu \mathrm{m} \times$ $5 \mu \mathrm{m}$ of each membrane were scanned by noncontact mode. The attenuated total reflectanceFourier transform infrared (ATR-FTIR) spectra of the samples were recorded by a Thermo Scientific FTIR model (NICOLET iS10, USA) over the wavenumber range of 4000-525 $\mathrm{cm}^{-1}$. Each spectrum results from 32 scans at $4 \mathrm{~cm}^{-1}$ resolution at a $45^{\circ}$ incident angle equipped with Diamond crystal.

\subsection{Gas Permeation Measurement}

Single Gas permeation test was performed at room temperature using $\mathrm{CO}_{2}$ with kinetic diameter of $3.3 \AA$. A stainless steel circular membrane cell with an effective permeation area of $7.065 \mathrm{~cm}^{2}$ was used. $\mathrm{CO}_{2}$ was fed at different pressure range from 1 to 3 bars. Prior to permeation test, the leak detection test was performed. The gas permeation rates were measured by a soap bubble flow meter, where the membrane permeance $(P / l)$ was calculated using

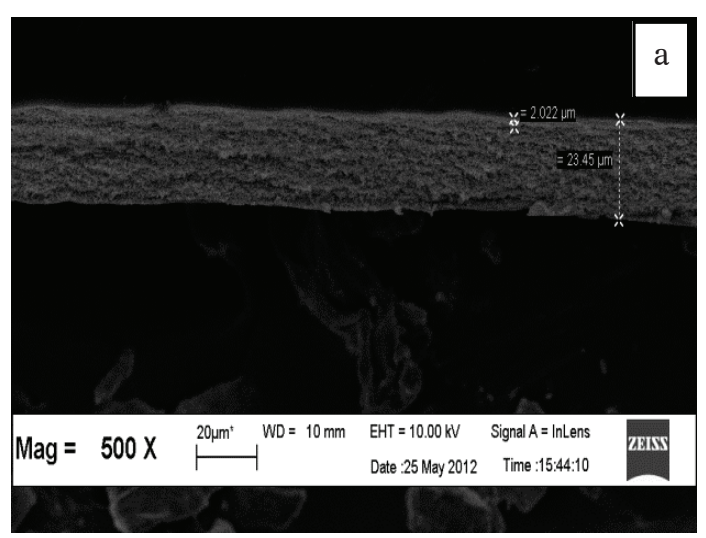

Eq. (1) and expressed in GPU [1 GPU $=1 \times 10^{-6}$ $\left.\left(\mathrm{cm}^{3}(\mathrm{STP})\right) /\left(\mathrm{cm}^{2} \mathrm{~s} \mathrm{cmHg}\right)\right]$.

$$
\frac{P}{l}=\frac{Q}{A \Delta p}
$$

Where $l$ is the thickness of membrane in $\mathrm{cm}$, $A$ is the effective membrane area in $\mathrm{cm}^{2}, Q$ is the measured volumetric flow rate (at standard temperature and pressure) in $\mathrm{cm}^{3} / \mathrm{s}$, and $\Delta p$ is the pressure difference across the membrane expressed in $\mathrm{cm} \mathrm{Hg}$. At least five specimens were tested for each sample and the average values, together with the standard errors, are reported. The standard error is estimated by the standard deviation divided by the square root of the sample.

\subsection{RESULT AND DISCUSSION}

Membrane morphologies for membranes formed via vacuum drying as well as solvent exchange drying method were compared through FESEM. Based on Figure 1, membrane that dried through conventional vacuum drying was found to have thickness of $23.63 \mu \mathrm{m}$ and top skin layer of thickness of $2.65 \mu \mathrm{m}$ (Figure 1a). Meanwhile, membrane dried via ethanol-hexane exchange drying method appeared to have thickness of $33.8164 \mu \mathrm{m}$ and top skin layer of thickness of $655.41 \mathrm{~nm}$ (Figure 1b). Membrane with conventional vacuum drying seemed to have the collapse of polymer structure and developed more

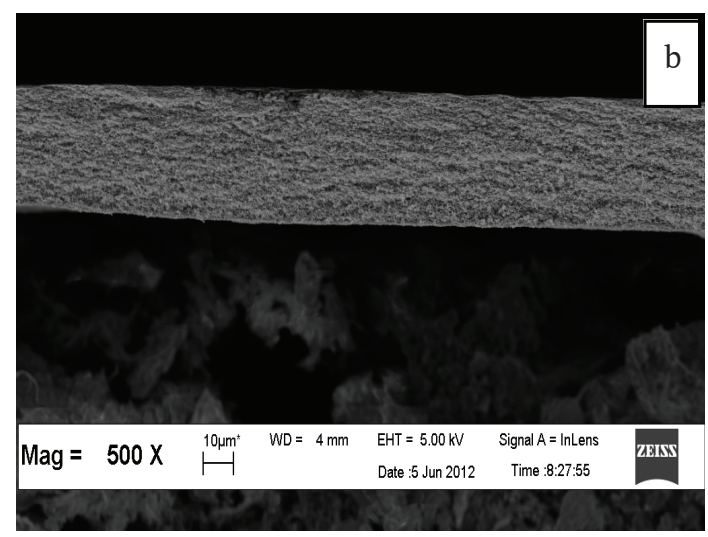

Figure 1 FESEM cross section micrograph of membrane with (a) vacuum drying (M1), and (b) solvent exchange drying (M2) 
compact polymer matrix. As compared the top layers in both membranes, M1 showed to have a much ticker thickness, which could be explained through following two main reasons. First, could be attributed to the faster water evaporation during vacuum drying as results of its higher surface tension and volatility, as shown in Table 1. Second, the remaining solvent within the pores that below the top layer may lead to plasticization of the polymer. Hence, a densification for the top layer is possible upon drying for M1. Whereby, during ethanol-hexane exchange drying, the water inside M2 was not evaporated but gradually replaced by ethanol first followed by hexane with less polarity and lower surface tension (Table 1), thus, it was prevented from the plasticization as well as densification [19].

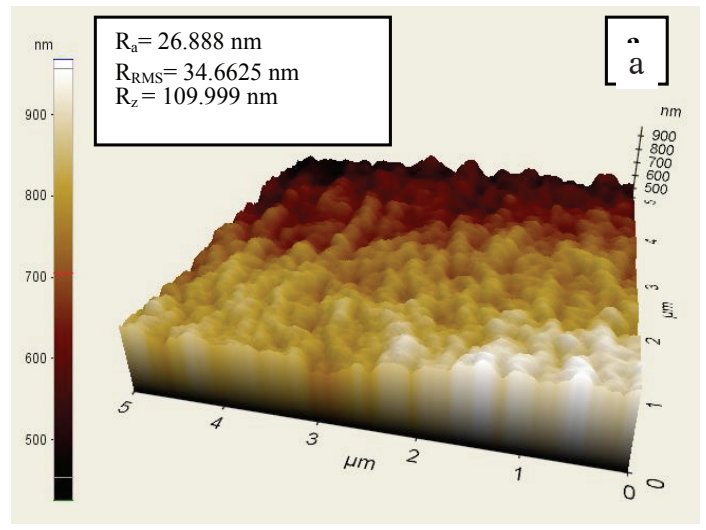

Table 1 Surface tensions of water, ethanol, and hexane [19]

\begin{tabular}{cc}
\hline Solvent & Surface tension $($ dyne $/ \mathbf{c m})$ \\
\hline Water & 72.5 \\
Ethanol & 22.7 \\
hexane & 17.9 \\
\hline
\end{tabular}

By comparing the roughness using AFM in Figure $2 a-b$, a rough membrane surface was found on the membrane that dried with conventional vacuum drying (M1), whereas membrane that dried under the solvent exchange method shown to have a smooth surface (M2). This is due to the faster water evaporation during vacuum drying compared to the slower evaporation rate in the case of solvent exchange.

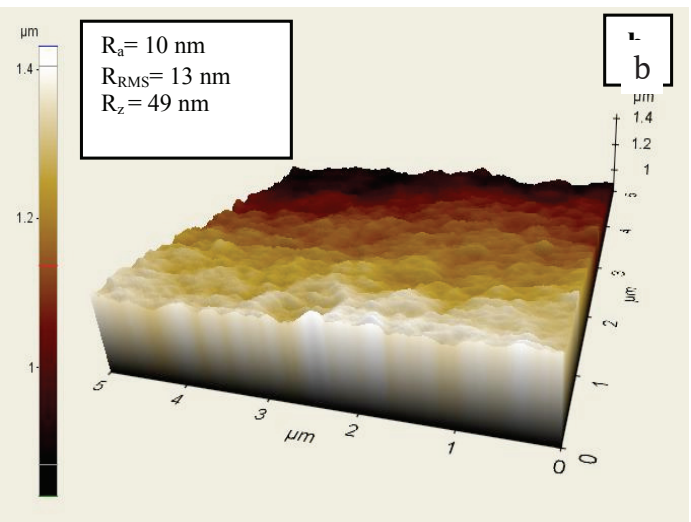

Figure 2 AFM roughness measurement for membranes dried with (a) vacuum drying (M1), and (b) solvent exchange drying (M2)

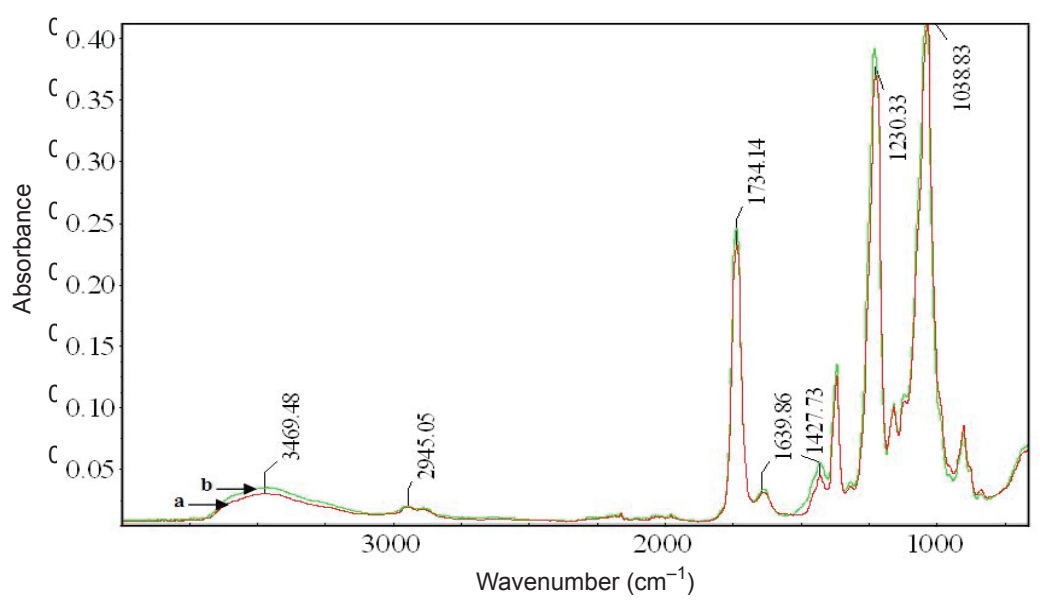

Figure 3 ATR-FTIR spectra of (a) M1, and (b) M2 
To further explained the different between these two drying method, the physicochemistry of both MMMs were considered. As shown in Figure 3, the M1 consists of absorption peaks at $3469.48 \mathrm{~cm}^{-1}, 2945.05 \mathrm{~cm}^{-1},(1734.14-1639.86)$ $\mathrm{cm}^{-1}, 1427.733 \mathrm{~cm}^{-1}, 1230.33 \mathrm{~cm}^{-1}$, and 1038.83 $\mathrm{cm}^{-1}$ for $\mathrm{O}-\mathrm{H}, \mathrm{C}-\mathrm{H}, \mathrm{C}=\mathrm{O}, \mathrm{C}-\mathrm{O}-\mathrm{H}, \mathrm{CH}_{3} \mathrm{CO}$, and $\mathrm{C}-\mathrm{O}-\mathrm{C}$, respectively (Figure $3 \mathrm{a}$ ). Meanwhile, higher absorption peaks of $\mathrm{O}-\mathrm{H}, \mathrm{C}-\mathrm{H}, \mathrm{C}=\mathrm{O}$, and $\mathrm{C}-\mathrm{O}-\mathrm{H}$ were indicated for M2 (Figure $3 \mathrm{~b}$ ). This observation has further verified the replacement of water by ethanol and followed by hexane. This might be due to the molecular affinity of ethanol and hexane that close to CA. The solubility for CA, ethanol, hexane, and water based on Hansen solubility are equal to 25.1, 26.2, 14.9, and 47.9 $(\mathrm{MPa})^{1 / 2}$, respectively $[20,21]$. According to the solubility rule, the closer their solubility are, the stronger their molecular affinity [3]. Thus, the molecular affinity are in the order of CA-ethanol $>$ CA-hexane $>$ CA-water.

\subsection{GAS PERMEATION PERFORMANCE}

The transport of gases through non-porous membranes is usually governed by the solutiondiffusion mechanism presence in all polymeric membranes [22]. In order to evaluate the specificity of the drying results, both M1 and
M2 were studied under $\mathrm{CO}_{2}$ permeation. Based on Figure 4, it is obvious that M2 with solvent exchange drying method gave higher $\mathrm{CO}_{2}$ permeance which is in the range of (733.90741.67) GPU compared to M1 with vacuum drying which is in the range of (18.72-18.44) GPU only. The higher permeation in M2 was due to the less drastic contraction of the membrane that avoid the collapse of membrane structure and disintegration [23, 24].

\subsection{CONCLUSION}

MMMs were developed from CA polymer and functionalized MWCNTs. Different drying methods (vacuum drying and solvent exchange drying) were used to evaluate its effects on the membrane morphologies and gas permeation performance. MMM that dried using solvent exchange technique appeared to have less compact skin layer with smoother surface. In term of performance, it was proven that M2 have a better permeance of (733.90-741.67) GPU compared to M1 (18.72-18.44) GPU within pressure range of 1 to 3 bars. In this study, ethanol-hexane exchange drying method was proven that able to maintain little impact on the membrane structure and improved the $\mathrm{CO}_{2}$ permeance.

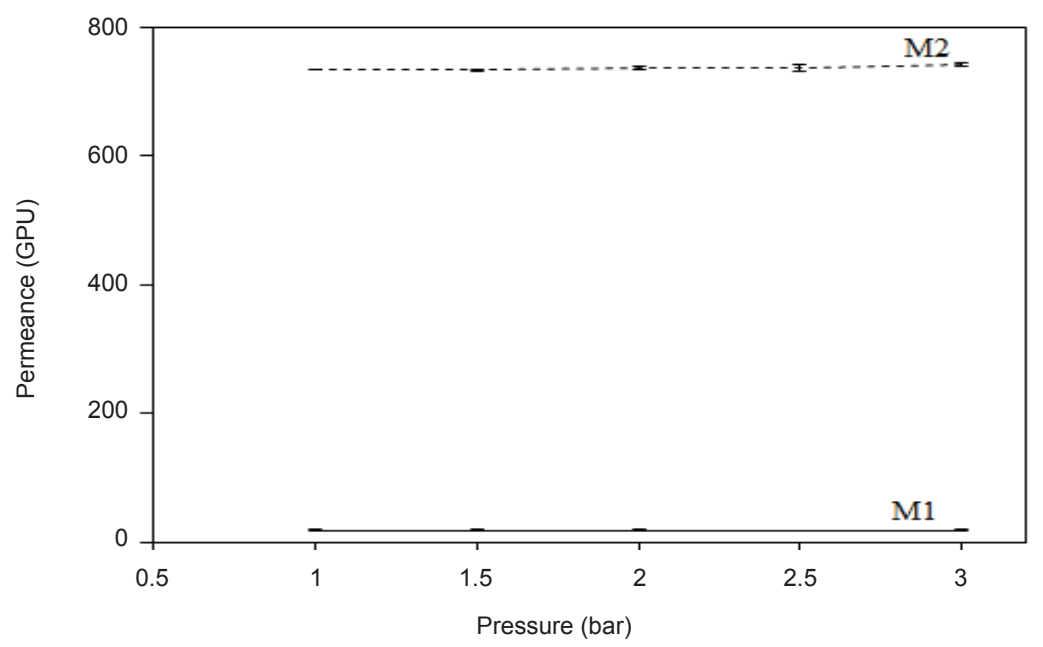

Figure 4 Permeance (GPU) of pure $\mathrm{CO}_{2}$ gas for membranes: M1, and M2 at different stand pressures 


\section{ACKNOWLEDGMENT}

The authors wish to thank the financial support granted by MOSTI Science Fund (Grant no: 305/PJKIMIA/6013386), FRGS (Grant no: 203/PJKIMIA/6071234), RU-PRGS (Grant no: 1001/PJKIMIA/8045029), and Universiti Sains Malaysia RU Membrane Cluster Science and Technology. Also, Z. A. Jawad acknowledges the University of Technology-Iraq for the financial support through pursuing her study.

\section{REFERENCES}

[1] Rodriguez, D. M. P. 2010. Aminosilanefunctionalized cellulosic polymers for increased carbon dioxide sorption. In: Chemical Engineering. Georgia Institue of Technology. 199.

[2] Kailash, C. K., C. Y. Feng, Takeshi Matsuura. 2007. Synthetic polymeric membranes characterization by atomic force microscopy. Springer: Ottawa. 197.

[3] Jie, X., Y. Cao, J.-J. Qin, J. Liu, and Q. Yuan. 2005. Influence of drying method on morphology and properties of asymmetric cellulose hollow fiber membrane. J. Membr. Sci. 246: 157-165.

[4] Riley, R., J. O. Gardner, and U. Merten. 1964. Cellulose acetate membranes: Electron microscopy of structure. Science 143: 801-803.

[5] Gantzel, P. K., and U. Merten. 1970. Gas separations with high-flux cellulose acetate membranes. Industrial \& Engineering Chemistry Process Design and Development 9: 331-332.

[6] Lui, A., F. D. F. Talbot, A. Fouda, T. Matsuura, and S. Sourirajan. 1988. Studies on the solvent exchange technique for making dry cellulose acetate membranes for the separation of gaseous mixtures. J. Appl. Polym. Sci. 36: 1809-1820.

[7] Kumbharkar, S. C., Y. Liu, and K. Li. 2011. High performance polybenzimidazole based asymmetric hollow fibre membranes for h2/co2 separation. J. Membr. Sci. 375: 231-240.
[8] Goh, P., A. Ismail, S. Sanip, B. Ng, and M. Aziz. 2011. Recent advances of inorganic fillers in mixed matrix membrane for gas separation. Sep. Purif. Technol. 81: 243264.

[9] Mahajan, R., R. Burns, M. Schaeffer, and W. J. Koros. 2002. Challenges in forming successful mixed matrix membranes with rigid polymeric materials. J. Appl. Polym. Sci. 86: 881-890.

[10] Ismail, A. F., P. S. Goh, S. M. Sanip, and M. Aziz. 2009. Transport and separation properties of carbon nanotube-mixed matrix membrane. Sep. Purif. Technol. 70: 12-26.

[11] Itta, A. K., H.-H. Tseng, and M.-Y. Wey. 2010. Effect of dry/wet-phase inversion method on fabricating polyetherimide-derived cms membrane for h2/n2 separation. Int. J. Hydrog. Energy 35: 1650-1658.

[12] Aroon, M. A., A. F. Ismail, M. M. MontazerRahmati, and T. Matsuura. 2010. Effect of chitosan as a functionalization agent on the performance and separation properties of polyimide/multi-walled carbon nanotubes mixed matrix flat sheet membranes. J. Membr. Sci. 364: 309-317.

[13] Moore, T. T., T. Vo, R. Mahajan, S. Kulkarni, D. Hasse, and W. J. Koros. 2003. Effect of humidified feeds on oxygen permeability of mixed matrix membranes. J. Appl. Polym. Sci. 90: 1574-1580.

[14] Jain, A. K., N. K. Acharya, V. Kulshreshtha, K. Awasthi, M. Singh, and Y. K. Vijay. 2008. Study of hydrogen transport through porous aluminum and composite membranes. Int. J. Hydrog. Energy 33: 346-349.

[15] Chou, W. L., D. G. Yu, and M. C. Yang. 2005. The preparation and characterization of silver-loading cellulose acetate hollow fiber membrane for water treatment. Polymers for Advanced Technologies 16: 600-607.

[16] Chen, J., M. J. Dyer, and M.-F. Yu. 2001. Cyclodextrin-mediated soft cutting of single-walled carbon nanotubes. J. Am. Chem. Soc. 123: 6201-6202.

[17] Jiang, L., T. Chung, and S. Kulprathipanja. 2006. An investigation to revitalize the 
separation performance of hollow fibers with a thin mixed matrix composite skin for gas separation. J. Membr. Sci. 276: 113-125.

[18] Zhang, X.-R., L.-Z. Zhang, H.-M. Liu, and L.-X. Pei. 2011. One-step fabrication and analysis of an asymmetric cellulose acetate membrane for heat and moisture recovery. J. Membr. Sci. 366: 158-165.

[19] Van't Hof, J., A. Reuvers, R. Boom, H. Rolevink, and C. Smolders. 1992. Preparation of asymmetric gas separation membranes with high selectivity by a dualbath coagulation method. J. Membr. Sci. 70: 17-30.

[20] Burke, J. 1984. Soulibility parameters: Theory and applications. In: The American Insitute of Conservation.

[21] Romero, R. B., C. A. P. Leite, and M. d. C. Gonçalves. 2009. The effect of the solvent on the morphology of cellulose acetate/ montmorillonite nanocomposites. Polymer 50: 161-170.

[22] Sanip, S. M., A. F. Ismail, P. S. Goh, T. Soga, M. Tanemura, and H. Yasuhiko. 2011. Gas separation properties of functionalized carbon nanotubes mixed matrix membranes. Sep. Purif. Technol. 78: 208-213.

[23] Minhas, B. S., T. Matsuura, and S. Sourirajan. 1987. Formation of asymmetric cellulose acetate membranes for the separation of carbon dioxide-methane gas mixtures. Ind. Eng. Chem. Res. 26: 23442348.

[24] Rahman, S. A. 2004. Development of defect-free and hyperthin-skinned of asymmetric cellulose acetate membrane from binary dope system for gas separation. in: Faculty of Chemical and Natural Resources Engineering. Universiti Technologi Malaysia. 141. 